\title{
PHILOSOPHICAL TRANSLATION ANALYSIS OF JEREMY MUNDAY'S INTRODUCING TRANSLATION STUDIES
}

\author{
Rofingudin Arrosyid', Satria Adi Pradana ${ }^{2}$ \\ State University of Yogyakarta ${ }^{1}$, UIN Raden Intan Lampung ${ }^{2}$ \\ Rofingudinarrosyid@gmail.com
}

\begin{abstract}
This study aimed to investigate the philosophical theory contained in Jeremy Munday's book. The data from this study were obtained from Jeremy Munday's book Introducing Translation Studies: Theories and Applications, published by Routledge, London, 2001. Literature study research method was used by reviewing the philosophy of translation theory from Jeremy Munday's book. After getting the relevant surveyors, the researchers identified the translation philosophy theory contained in the book. From the results of the book's investigations, it was known that some experts were trying to introduce the philosophical theory of modern translation. In contrast, the experts and their fields of study were George Steniner, who researched on the theory of interpretation of meaning, Ezra Pound, who researched on the power of language, Walter Benjamin was about the purity of the translator's task, and Derrida who researched about the relationship between deconstruction translation (text reading method). In addition, there are also several case studies related to the application of the philosophical theory of language strategies put forward by these experts. All of these translation theories discussed the principles of translation and their relation to improving translation studies.
\end{abstract}

Keywords: Jeremy Munday's Book, Literature Study, Theory of Translation Philosophy.

\section{INTRODUCTION}

There are a lot of explanations about translation. According to Wikipedia, translation is the process of interpreting the meaning of a text in the source language in order to create equivalent text in the target language that communicates the same 
message. According to Oxford, translation is the communication of messages from the source language to the target language by using the equivalent text.

According to Catford (1965: 20), translation is "the process of substituting textual material in one language (Source Language) for equivalent textual material in another language (Target Language)." It is the process of substituting textual material in one language for its equivalent in another language. Catford argued that in ordinary translation, not all discourse is transferred into the target language equivalent.

Sudarno (2011) stated that translation is a diversion of thoughts or ideas from one source language (SL) into another language (TL). Translation is changing the source language text into the target language text (TL) by considering the meaning of the two languages and it has to be as similar as possible. The most important thing is the translation must follow the rules in the target language.

Meanwhile, Munday (2001: 5) argued that translation is a transfer of the source language into the target language in the form of written text. Translation (Newmark, 1986: 5) is the rendering of meaning from text to another language based on the intended text.

Based on the explanations above, it can be concluded that translation is a series of actions taken by the translator when translating the source (or original) text (SL) into another language (TL). Thus, it can be seen that each theory has its own philosophical approach, especially those related to translation. Afterward, it can be further studied so 
that we can know the philosophical approach of each translation theory. One of the theories is the theory of James Munday.

\section{RESEARCH METHODOLOGY}

In this research, literature study was used as the method. M. Nazir explained that literature study is a data collection technique by conducting study towards books, literature, notes, and reports and it is related to the problem solving." (Nazir, 1988: 111).

The data from this research were obtained from Jeremy Munday's book entitled "Introducing Translation Studies: Theories and Applications" which was published by Routledge, London, in 2001, as well as other articles and books that support this research.

\section{The Philosophical Approach in the Work of Jeremy Munday}

Munday argued that philosophical approach to translation aims to reveal the essence of the act of translation. In one of his books, Munday included several philosophical thoughts of modern translation put forward by several experts such as George Steniner who researched on the theory of interpretation of meaning, Ezra Pound who researched on related to the power of language, Walter Benjamin was about the purity of the translator's task, and Derrida was about the relationship between translation and deconstruction (text reading method). (Munday, 2011: 162). 


\section{A. Steiner, Hermeneutic Theory}

Steiner defined the Hermeneuitic Approach is a theory of interpretation of meaning by investigating the meaning of understanding spoken or written texts. This theory is used to diagnose the process of understanding meaning in general. Since the 18th century, an investigative system has been designed about the theory and process of translation, while Steniner focused on translation's psychological and intellectual functions (Munday, 2011: 163).

Steiner described hermeneutics motion in translation is as an act of meaning and transfer of precise meaning. The concept of translation is not as a science but as an exact art. Translation is done appropriately in the sense which can be carried out not systematically. Hermeneutic motion consists of four parts, namely (1) initiative trust; (2) aggression (or penetration); (3) incorporation (or embodiment); and (4) compensation (or restitution).

\section{Initiative trust}

The first step in translation is "investment of belief", which considers and believes that the source language (SL) can be understood. In the case of translation, SL is assumed to be something real and can be translated. At this stage, rhymes and noncommunicative words may not be translated. This stage contains two risks.

The translation might have the whole meaning like the medieval Bible translations to convey the whole message. The translated word can be meaningless because the form and meaning are closely associated with not being translated. 


\section{Aggression}

The second step, translation takes the core meaning (extract) from SL by penetrating or finding the meaning. So, it can be understood by the target reader.

\section{Incorporartion}

The third step, the source language which has been taken in essence is then brought to the target language (TL) which has its own word or term and meaning. At this stage, there are two different poles between the source language and the target language. There is a possibility that cultural inconsistency exists and even requires more efforts to translate, so creativity is needed to produce the target language. It is also necessary to concern to the danger of inequal meaning.

\section{Compensation}

The feedback from the core of the translation to the target culture is not against ST. Text may be lost or added as transfer concequences.

An imbalance between the source language and the translation products may occur in an effort to create a harmonious system in translation. An imbalance in translation can be compensated, for example, the target language is less than the original (ST). The most important thing is to achieve proper meaning by equality.

A moral element and balance in translation theory is not only in the traditional type (literal, free, faithful) of translation, especially in literary translation. A good 
translation is defined as reflecting two languages, the history of communication, and its growth.

Steiner also argued that modern translation theory can suppress the influence of foreign languages into the target culture in equating good translation with appropriate domestication. Translators need to concern on the ideological strategies of domestication and foreignization. Another criticism of translation is that the product of translation is still considered to be male-dominted language.

\section{B. Ezra Pound, Energy language}

In the 21st century, Ezra Pound's modern poetry takes on the theme of criticism and translation acts. Pound tried to find the language power by examining, researching, observing the quality of language expression, observing the energy of language through

clarity of rhyme, voice, and form of translation and finding energy in an image or work influenced by the literature behind it, for example Latin and Anglo Saxon literature, and Ital poetry. (Munday, 2011: 167)

Pound experimented and explored poetry to inspire other translators by looking at ideas in literary works. Translation has been described as a tool in the cultural struggle (Gentzler 2001: 28). Through translation criticism and creative forms of translation also influence the results in literary works.

\section{Walter Benjamin, Translator's task}


The statement above concluded that the original translation is transparent; it does not obscure its original form, does not preclude it but allows a pure translation. The real translation is more concerned with words rather than sentences.

A good translation must be able to express the relation between two languages, so that there is a sense of harmony from language differences. It takes creativity and development of translation to contribute to the two languages. In the end, the translation results can achieve all aspects including syntax elements, words and sentences as the main elements in translation.

\section{Desconstruction (deconstruction)}

Cristopher Norris in his book entitled "Desconstuciton: Theory and Practice" introduced deconstuction as an act of what is done to language, experience, and the norms of possibility in human communication (Munday, 2011: 170)

It seeks to undo both a given order of priorities andthe very system of conceptual opposition that makes that order possible ... Deconstruction is ... an activity of reading which remains closely tied to the texts it interrogates. (Norris 1991:

Considering to the statement above, it can be concluded that the deconstruction dismantles some of the key assumptions of linguistics, starting from the clear division initiated by Saussure regarding signs and markers and concepts that define, capture, and stabilize meaning. Derrida concluded that deconstruction is the act of the subject uncovering an object composed of various elements which deserves to be dismantled. 
Derrida doubted Jakobson's theory regarding the division of 3 types of translation, namely interlingual, intralingual, and intersemiotic. Derrida showed the incoherence of Jakobson's definition of an interlingual translation or actual translation.

Derrida's work title includes words as he presented on his own translation of Shakespeare's work entitled "the merchan of venice" and "when mercy season justice". Derrida tried to implement translation as a concept and practice that reflects the results of theories and translators to produce syntax, lexicon, and typography into English (Venuti in Derrida: 2001: 174-200). The foreignization strategy can be used as an example as follows:

- Changing the punctuation, remove italics, and add parentheses and quotes in important technical terms;

- Adding the suffix, métaphorique becomes metaphor rather than metaphorics;

- Omitting precision in the translation of linguistic and philosophical terms, e.g effet, valeur and articulationare are given as phenomena, and shared ideas;

- Changing the syntactic and discursive sequences;

- Failure to create role of words: translation is more than a metaphor.

Based on the above explanation, Lewis considered that English translation of "white mythology" fails to achieve an acceptable translation due to the emergence of the French text. Derrida's steps in deconstructing text ideas are not in English. Another strategy is needed, namely the experimental translation strategy introduced by Lewis, which is used mainly to solve some problems in translating philosophical texts where 
the text deconstructs the old language. This approach is quite interesting because it uses the elements from constructive discourse analysis in examining management philosophy from an interdisciplinary perspective.

\section{Case study 1}

This case study attempts to translate a poetry based on Steiner's hermeneutic translation strategy. The poetry is a poem by Seamus Heaney which was translated into Irish. This poem is called Beowulf (epic poem), translated from Anglo-saxion (old English language originating from Germany) and Scandinavia. This poem was published in the UK in 1999 and got so many positive attentions and won the prestigious Whitbread award. Heaney introduced the process of translating and constructing modern languages to the ancient epic that was stuck thousands of years ago.

Heaney (1999) described that the peculiar British poetry still seeks to the meaning and has a basic Anglo-Saxon language and Scandinavian culture. The temporal shift and culture of the Aglo-Saxion language was still pervaded.

As the first step, Steiner's hermeneutic motion approach was used to understand the meaning of the original poetry. Even though this poem was originally from overseas, Heaney tried hard to translate it. The text might tend to Anglo-saxion, but it is tried to make a distinction and great translation.

There is speculation between old and modern readers. Nowadays, the metaphor showed an oddity, it reminds the situation of Anglo-Saxon in England into the 
millennium era. The metaphors tend to differ in conveying the idea which is called "open-cast mine" by Steiner.

The translation strategy is also to fulfill personal needs and the foundation of translation with biography and language as one of the ways like Irish poetry, which covered a complex history of power, colonies, resistance, integration, and antagonism. Cultural and linguistic elements in translation are related to the source and target languages.

\section{Discussion on case study 1}

The first case study attempts to see how philosophical approaches are used in modern translation practice. Heaney showed indications of how to search for language and question language early in translation, playing an integral part in constructing modern Beowulf (epic poetry). Translation deliberately connects past culture (anglosaxion and Scandinavian) and the culture and language discussed, Irish, the language

of translation elevates between past and present languages, transfers myths into a common language, confuses pre-existing ideas, by refining them with hermeunutic theory as there are existing opinions on post-colonial theory. It tries to explain the closeness between practice and translation of modern literary works based on interpretation theory.

Case study 2 
In this case study, the text is a short story entitled "Nineve" by the Argentine author, translated by Hector Lebertella. It contains a story about the British archaeologist, Henry Rawlinson. Libertella uses illustrations, questions and delves into the archaeologist by trying to understand his inspections. It is interesting to see the extent of the approach adopted by Derrida and Lewis regarding the text. The main theme of this short story is hope and ignorance that is conveyed in confusing words.

\section{Discussion on case study 2}

The translation strategy used is similar to 'abusive fidelity' by Lewis, which attempts to create the energy of the source language by experimenting with risks and conflicts with the norms of the target language. This is important because translation is not the form of the word but also knows its essence. The focus of translation should be on understanding the core themes that define the entire text. Creativity is needed in forming or designing in the target language.

Derrida tried to minimize the difference between SL and TL in the elements of the Libertella text. The two texts between Sir Rawlinso in Spanish and Sir Henri in English were equated. The translation is more refined without ignoring the original text, although the reader will be surprised by the presence of Spanish elements.

Experimental translation strategy gets a clearer translation results. The application may be more correct in philosophical texts. Related to Libertella's Nineve, using conventional strategies cannot create original energy. Nineve translation was not 
included in the UK publication because the target audience could not understand the translation.

\section{CONCLUSION}

The explanation above illustrates several experts' perspectives on the theory of translation philosophy. In After Babel (1975), Steiner referred to the German hermeneutic tradition, a translation based on the interpretation of meaning, particularly in literary texts. Ezra Pound emphasised the vitality of the translation language in his translation, whereas Walter insisted on the translator's task being brief and pleasant in terms of maintaining the language's purity through literal translation. Meanwhile, Derrida's description, the certainty that the translation holds, incorporates the conflict between the source and target languages as the linguistic symbols' stability. Each of these translation theories discussed the fundamentals of translation and how they relate to the advancement of translation studies.

\section{REFERENCES}

Benjamin, W. 1969/2004. The task of the translator. translated by H. Zohn, in L. Venuti Catford, J. 1965. A Linguistic Theory of Translation. Oxford: Oxford University Press.

2001/2004. What is a "relevant" translation?. translated by L. Venuti, Critical Inquiry, reprinted in L. Venuti (ed.) (2004).

Gentzler, edwin. 2001. Translation, hypertext, and creativity: contemporary translation theories. Bristol: multilingual matters. 
Graham, J. F. 1985. Difference in Translation, Ithaca, New York: Cornell University Press.

Heaney, S. 1999. Beowulf. London: Faber and Faber.

Munday, J. 2001. Introducing Translation Studies: Theories and Applications. London: Routledge.

Norris, C. 1991. Deconstruction: Theory and Practice. London and New York: Routledge.

Pound, E. 1918/2004. Guido's relations, in L. Venuti (ed.) (2004)

Sudarno, A.P. 2011. Penerjemahan Buku Teori dan Aplikasi. Surakarta : UNS Press https://id.wikipedia.org/wiki/Terjemahan ( Diakses pada tanggal 5 Januari 2021 ) 